\title{
Current State of Medical Education in India: A Perspective
}

\author{
${ }^{1}$ Nilesh Chandra, ${ }^{2}$ Mohit Mehndiratta, ${ }^{3}$ Seema Garg, ${ }^{4}$ Dinesh Puri
}

\begin{abstract}
Introduction: Advances in biochemical sciences have led to a significant progress in medical treatment. However, not much change has been made in the medical school curricula.
\end{abstract}

Current teaching practices and lacunae: Medical schools follow didactic teaching. Policy makers hark on the pedagogical skills of the medical educators. However, one should talk about the "andragogical skills" of a medical educator. Adults approach learning in a way fundamentally different from children. Our country is still far away from fully adopting innovative teaching methods for medical education. There is absence of strong teacher-training programs.

The way forward: Regulatory body for medical education has emphasized need based curriculum. Large scale training of the faculties of all medical colleges has been initiated. However, the scope and pace of all such activities is probably insufficient. Consideration should be given to shift towards andragogical approach, robust teacher-training programs and earnestly implementing innovative teaching methodologies for medical education.

Key words: Andragogy, Didactic teaching, Medical education, Medical Curriculum, Innovative teaching methodologies, Teacher training program.

How to cite this article: Chandra N, Mehndiratta M, Garg S, Puri D. Current State of Medical Education in India: A Perspective. Indian J Med Biochem 2018;22(2):157-159.

\section{Source of support: Nil}

Conflict of interest: None

\section{INTRODUCTION}

Over the last two decades, there has been an explosion in medical knowledge, and great leaps have been made in the understanding and approach to management of the disease. Today, we are looking at the pathophysiology of disease at molecular ${ }^{1}$ and biochemical levels, and in perspective of gene-environment ${ }^{2,3}$ as well as

\footnotetext{
${ }^{1,3}$ Assistant Professor, ${ }^{2}$ Associate Professor ${ }^{4} \mathrm{Head}$ and DirectorProfessor

${ }^{1}$ Department of Biochemistry, Subharti Medical College, Delhi, India

${ }^{2-4}$ Department of Biochemistry, University College of Medical Sciences, Guru Teg Bahadur Hospital, Delhi, India

Corresponding Author: Mohit Mehndiratta, Associate Professor, Department of Biochemistry, University College of Medical Sciences, Guru Teg Bahadur Hospital, Delhi, India, Phone: +91 981844635, e-mail: drmohitucms@gmail.com
}

gene-gene interaction. ${ }^{4}$ Moreover, increasingly, multiple biochemical pathways are being elucidated concerning causation of disease, made possible by processing of data by new, improved, powerful and sophisticated software. ${ }^{5}$ These advances in biochemical sciences have led to significant progress in medical treatment.

In spite of such profound changes in the fundamental approach to medical sciences, not much change has been achieved in the medical school curriculam. Indeed, in most medical colleges in India, the curriculum has remained unchanged over the last two decades. Although, the medical council of India (MCI) has frequently stressed upon need-based curriculum, significant attention has not been given to the necessity of overhauling the curriculum. ${ }^{6}$

\section{CURRENT TEACHING PRACTICES AND LACUNAE}

The currently followed traditional curricula in medical schools follow didactic teaching which is examination oriented and presents the different subjects in isolation of one another. ${ }^{7}$ Rarely is an attempt made to deliver the importance of the topic under discussion in the larger perspective as a part of the biological system in relation to the other subjects. In this context, it is pertinent to mention that numerous educators and policymakers hark on the pedagogical skills of the medical educators (rather the lack thereof), but one important fact which is not given due consideration is the following: "Medical students are not children but grown-up adults!" Just like we cannot extrapolate the treatment used for adults for the treatment of children by rationalizing children as "just incompletely grown humans," we cannot extrapolate the tried and tested teaching methodologies for children onto fully grown adults. Thus, rather than the "pedagogical skills" of a medical educator, one should talk about the "andragogical skills" of a medical educator.

Children have classically been taught in a well-structured format, and the teacher has traditionally directed the flow of knowledge. Because children do not have already formed a knowledge base or specific relevant experiences, this structure of teaching has borne the need for imparting knowledge to children in a satisfactory manner. However, the same has not been found to provide good results for adults. Indeed, the various "innovative teaching methodologies" have discarded the classical pedagogical approach to teaching, and have 
produced better results. ${ }^{8}$ The most common theme of all these methodologies is the understanding that adults approach learning in a way, which is fundamentally different from children. There are two main stumbling blocks in the application of pedagogy to adult teaching. First is that the adults expect to know the necessity for learning something. Second is that the adults have more interest in learning topics which have immediate relevance to their personal lives or professional progression.

Andragogy, as advocated by Knowles, makes several assumptions about the motivation of adult learning. ${ }^{9}$ Adults are more interested in 'learning by doing.' If adults are involved in the planning of their instruction and are made responsible for their decision on content, the motivation levels skyrocket to unforeseen heights. Adults want to know why they are learning something. They are motivated to participate in learning only if it is possible to use this information to resolve a potential problem, rather than for the content of the knowledge itself.

Moreover, the matter at hand should have immediate relevance to their work. If the learning activities are based on experience, with scope for committing mistakes, the retention and the interest in the content is much more than the traditional didactic mode of teaching. Finally, adults work better with internal motivators rather than external motivators.

Besides advancement on the knowledge front of medical education, there has also been an attempt at a host of teaching innovations all over the world, particularly in the field of medical education. However, the same has not been made much headway in the Indian scenario. Moreover, in the absence of mandatory feedback framework, the efficacy of any such advancement cannot be gauged. Incorporation of a student-centric feedback mechanism is to sure to lead to tremendous improvement in the state of medical education in India.

Another lacuna in the advancement of medical education is the absence of strong teacher-training programmes. Indeed, with the flurry of medical colleges popping up in the country, the required qualifications of the faculty, which were already at a minimal level, have been further diluted. Also, the attempt at improving the scenario is not as desired. Most of the faculty in the country today have never attended a training programme, where exposure to basic tenets of an educator may have been provided. Almost all the current teaching faculty has acquired their teaching skills, minimal and untested as they are, 'on the job.' This 'test by fire' does not necessarily produce good educators; quantity of experience gained as a 'teacher' is well documented, but the poor quality of such experience, the absence of formative assessment and no incentive to improve the presentation skills directed towards engaging the students are hardly ever acknowledged.

\section{THE WAY FORWARD}

The regulatory bodies and the government are fully seized of the problems besieging the medical education in India and have taken several praiseworthy steps to improve the situation. As mentioned before, they have repeatedly emphasized upon need-based curriculum, and all universities have been granted full freedom to design and implement their curricula without interference from the said body. Large-scale training of the faculties of all medical colleges has been initiated and even been made compulsory to some extent to improve the quality of teachers imparting education and training to our future doctors. ${ }^{10}$ Latest teaching tools are being incorporated in various medical colleges all over the country, and the central government bodies are extending monetary and logistical support to such programmes in the form of grants, training, and personnel, wherever possible. All such steps taken by the concerned authorities are laudable and will go a long way in improving the situation prevalent today in the country. However, the scope and pace of all such activities are sadly lacking in terms of the actual goal to be achieved.

The problems plaguing the medical education system are not hidden from the concerned authorities and the various parties having a stake in it. However, one of the major stumbling blocks in resolving these issues is simply the inertia inherent in the system. Just like any other field, change is not very readily acceptable, palatable or welcome. Hence, the first step towards the resolution of various ills is the development of resolve and intention to see the changes through. Most of our current administrators are well-intentioned, and the same is seen in the various resolutions and recommendations being presented by them, but the intensity to follow through with the same is missing. If enough attention is given to execute a robust teacher-training program across the country in a concerted manner, it will immediately elevate the standard of medical education by several notches without any other intervention.

Similarly, by incorporating and shifting towards the andragogical concept of teaching, students can be made active participants and willing stakeholders in raising the bar of education standards in the medical field. Based on our studies, we have found that the opinion of the students (feedback) must be duly considered and addressed to make things more acceptable. ${ }^{11}$ Lastly, we also found that the students prefer innovative teaching methodologies like role play, problem-based learning 
and small group discussion over and above the traditional methods of teaching. ${ }^{12,13}$ Thus, an earnest implementation of innovative teaching methodologies will go a long way in transforming the medical education in India to a truly world-class level that will reflect in better patient care.

\section{REFERENCES}

1. Urmaliya V, Franchelli G. A multidimensional sight on cardiac failure: uncovered from structural to molecular level. Heart Fail Rev. 2017 May;22(3):357-370.

2. Ottman R. Gene-Environment Interaction: Definitions and Study Designs. Prev Med. 1996;25(6):764-770.

3. Waken RJ, de Las Fuentes L, Rao DC. A Review of the Genetics of Hypertension with a Focus on Gene-Environment Interactions. Curr Hypertens Rep. 2017 Mar;19(3):23.

4. Dato S, Rose G, Crocco P, Monti D, Garagnani P, Franceschi C, et al. The genetics of human longevity: an intricacy of genes, environment, culture and microbiome. Mechanisms of ageing and development. $2017 \mathrm{Jul}$ 1;165:147-155.

5. Li J, Wei Z, Hakonarson H. Application of computational methods in genetic study of inflammatory bowel disease. World J Gastroenterol. 2016 Jan 21;22(3):949-960.
6. Sood R. Medical education in India. Med Teach. 2008;30(6): 585-591.

7. Sood R, Ananthakrishnan N. Curriculum design India (PDF Download Available) [Internet]. ResearchGate. [cited 2017 May 21]. Available from: https://www.researchgate.net/ publication/281440766_Curriculum_design_India.

8. Prickel D. The Influence of New and Emerging Theories on Teaching Practices [Internet]. donart. [cited 2017 May 26]. Available from: http:/ / oregonstate.edu/instruct/ed553/donart.html

9. Knowles M. The modern practice of adult education: From pedagogy to andragogy. Wilton, Connecticut: Association Press; 1980.

10. Srinivas DK, Adkoli B. Faculty Development in Medical Education in India: The Need of The Day. Al Ameen J Med Sci. 2009;2(1):6-13.

11. Mehndiratta M, Garg S, Kar R, Puri D. Pitfalls of currently practiced approach for teaching medical students: opinions \& options. International Journal of Clinical Biochemistry and Research. 2016;3(1):100-104.

12. Mehndiratta $M$ and Puri D. Adopting role play for training medical interns about sample collection and processing for laboratory investigations. Ind j of Med Biochem 2015;19(1):24-27.

13. Mehndiratta M, Gupta S and Puri D. Roleplay: a method of teaching biochemistry to medical undergraduates. Ind $j$ of Med Biochem 2015;19(1):39-41. 